\title{
Identifikasi Potentially Inappopriate Medication (PIM) Pada Resep Pasien Diabetes Melitus Usia Yang Keluar Dari 3 Rumah Sakit di Sulawesi Utara
}

\author{
Weny Indayany Wiyono*,Widya Astuty Lolo*,Gayatri Citraningtyas* \\ Prodi Farmasi, Fakultas MIPA Universitas Sam Ratulangi
}

\begin{tabular}{l} 
KA T A KUNCI \\
\hline PIM, \\
Geriatri \\
Diabetes Melitus
\end{tabular}

\begin{abstract}
A B S T R A K
Latar Belakang. Penduduk lanjut usia atau geriatrik tidak dapat dipisahkan dari kondisi kesehatan. Hal tersebut mendorong pentingnya mengidentifikasi adanya ketidaktepatan peresepan bagi pasien lanjut usia khususnya pada pasien yang menderita Diabetes Mellitus (DM). Prevalensi DM di Sulawesi Utara mengalami kenaikan. Penelitian ini bertujuan untuk mengidentifikasi Potentially Inapopriate Medication (PIM) pada Resep pasien DM lanjut usia yang keluar dari Tiga Rumah sakit (RS) terletak di kota dengan prevalensi DM terbanyak di Sulawesi Utara. Metode. Penelitian dilakukan pada RS A Kota Manado, RS B Bitung dan RS C Tomohon. Penelitian ini menggunakan metode deskriptif kuantitatif secara retrospektif dengan mengambil data rekam medis setiap 3 bulan per Rumah Sakit lalu membandingkan dengan Beers Criteria 2015. Hasil. Kejadian PIM pada Resep Keluar Pasien DM Lanjut Usia di RS A, RS B dan RS C sebesar 81,26\%, 40,91 \% dan 37,38\% secara berturut-turut. Klasifikasi PIM terbanyak yaitu PIM dan Kelas Obat yang harus dihindari pada lanjut usia $(50,00 \%, 66,67 \%, 73,91 \%)$. Golongan Obat terbanyak dalam PIM yaitu Sistem Gastrointestinal khususnya Pemblok Pompa Proton $(30,47 \%)$
\end{abstract}

KEYW OR D S

PIM

Geriatric

Diabetes Mellitus

\begin{abstract}
A B S T R A C T
Background. Elderly or geriatric population can't be separated from health conditions. This encourages the importance to identifying the inaccuracy of prescribing for elderly patients, especially in patients with Diabetes Mellitus (DM). The prevalence of DM in North Sulawesi has increased. This study aims to identify Potentially Inapopriate Medication (PIM) in prescriptions for elderly DM patients who are discharged from the Three Hospitals (RS) located in the city with the highest prevalence of DM in North Sulawesi. Method. The study was conducted at Hospital A at Manado City, Hospital B at Bitung and Hospital $\mathrm{C}$ at Tomohon. This study used quantitative descriptive method retrospectively by taking medical record data every 3 months/Hospital and then comparing with the 2015 Beers Criteria. Results. The incidence of PIM in the Out Prescription for Elderly DM Patients in Hospital A, Hospital B and Hospital C was 81.26\%, 40.91\% and 37.38\%, respectively. Most PIM classifications are PIM and Drug Class which must be avoided in the elderly $(50.00 \%, 66.67 \%$, 73.91\%). The most drug group in PIM is Gastrointestinal System especially Proton Pump Inhibitors (30.47\%)
\end{abstract}

TERSEDIA ONLINE

31 Oktober 2019

Pendahuluan

Penduduk lanjut usia atau disebut geriatric tidak dapat dipisahkan dari kondisi kesehatan yang dipengaruhi perubahan farmakokinetik dan farmakodinamik (Fick et al, 2008), adanya komorbiditas, polifarmasi, status sosial ekonomi (Zeeny et al, 2017). Hal tersebut mendorong

*Corresponding author: Program Studi Farmasi, Fakultal Matematika dan IImu Pengetahuan Alam, Indonesia

Email address: winnie_indayany@yahoo.co.id

Published by FMIPA UNSRAT (2019) 
pentingnya mengidentifikasi adanya ketidaktepatan peresepan bagi pasien lanjut usia khususnya pada pasien yang menderita penyakit kronis. Salah satu penyakit kronis yang dapat dialami pada lanjut usia yaitu Diabetes Mellitus (DM) tipe 2. (WHO, 2019)

Menurut Riskesdas 2013, Prevalensi DM di Sulawesi Utara mengalami peningkatan dari Riskedas 2007. Tiga Kota merupakan kota yang memiliki prevalensi penderita Diabetes Melitus tertinggi di Sulawesi Utara yaitu Manado, Tomohon dan Bitung. Prevalensi DM di Manado, Tomohon, Bitung yaitu sebesar 2,70\%, 2,50\%, 1,60\% secara berturut-turut. Peningkatan prevalensi DM mendorong lebih dilakukan monitoring terhadap peresepan pasien untuk menghindari terjadinya Reaksi Obat yang tidak dikehendaki.

Reaksi obat yang tidak dikehendaki dapat dicegah dengan mengidentifikasi pengobatan berpotensi tidak tepat disebut potentially inapopriate medication (PIM) dan interaksi obat. (Zeenny et al, 2017) Pada pasien DM lanjut usia, kejadian reaksi obat yang tidak dikehendaki dan interaksi obat harus dihindari karena dapat menyebabkan kejadian masuk rumah sakit, morbiditas bahkan kematian (Yakaryilmaz et al, 2017; Routledge et al, 2004. )Penelitian ini bertujuan untuk mengidentifikasi PIM pada Resep pasien Diabetes Melitus lanjut usia yang keluar dari Tiga Rumah sakit di Sulawesi Utara dengan prevalensi DM terbanyak di Sulawesi Utara.

\section{Material dan Metode}

Penelitian dilakukan pada 3 Rumah Sakit di Sulawesi Utara antara lain 2 Rumah Sakit Pemerintah dan 1 Rumah Sakit Swasta. RS A merupakan RS Tipe A di Kota Manado, RS B merupakan RS tipe $\mathrm{C}$ di Bitung dan RS $\mathrm{C}$ merupakan RS Tipe $C$ di Tomohon. Periode Penelitian dilaksanakan selama 12 bulan. Penelitian ini menggunakan metode deskriptif kuantitatif yang dilakukan secara retrospektif dengan mengambil data rekam medis pasien selama 3 bulan per Rumah Sakit. Penelitian ini menidentifikasi Potentially Inappopriate Medication (PIM) menggunakan Beers Criteria 2015.

Proses identifikasi PIM dilakukan dengan membandingkan resep keluar dengan daftar Beers Criteria 2015. Kriteria inklusi yaitu pasien lanjut usia $\geq 45$ tahun, pasien yang didiagnosa Diabetes Melitus tipe 2. Kriteria eksklusi yaitu pasien yang meninggal selama dirawat dan pasien yang pulang paksa

\section{Hasil dan Pembahasan \\ Penelitian dilakukan pada 3 Rumah Sakit yang terletak di Sulawesi Utara. Pada RS A didapatkan 32 pasien lanjut usia, RS B didapatkan 66 pasien dan RS C didapatkan 45 pasien. Total sampel yang didapat 143 pasien.}

\section{Potential Inappopriate Medication (PIM) pada RS A}

PIM yang terjadi pada RS A sebesar 48 kejadian pada 26 pasien dari 32 pasien. Jumlah PIM yang terjadi pada pasien yaitu
Tabel 1. Jumlah PIM berdasarkan Jumlah pasien di RS A

\begin{tabular}{|c|l|l|}
\hline & Jumlah & Persentase \\
\hline Pengobatan tanpa PIM & 6 & $18,75 \%$ \\
\hline Pengobatan dengan PIM & 26 & $81,25 \%$ \\
1 PIM & 11 & $34,37 \%$ \\
$\geq 2$ PIM & 15 & $46,87 \%$ \\
\hline
\end{tabular}

Tabel 2. Klasifikasi PIM berdasarkan Beers Criteria 2015 di RS A

\begin{tabular}{|l|l|l|}
\hline Klasifikasi PIM Jumlah & Persentase \\
\hline $\begin{array}{l}\text { PIM dan Kelas Obat yang } \\
\text { harus dihindari pada } \\
\text { lanjut usia }\end{array}$ & 24 & $50,00 \%$ \\
\hline $\begin{array}{l}\text { PIM dan Kelas obat yang } \\
\text { harus dihindari pada } \\
\text { lanjut usia dengan } \\
\text { penyakit dan sindrom } \\
\text { tertentu obat dapat } \\
\text { memperparah }\end{array}$ & 1 & $2,08 \%$ \\
\hline $\begin{array}{l}\text { Obat yang digunakan hati- } \\
\text { hati pada lanjut usia }\end{array}$ & 16 & $33,33 \%$ \\
\hline $\begin{array}{l}\text { Interaksi Obat-obat yang } \\
\text { harus dihindari pada } \\
\text { lanjut usia (non infeksi) }\end{array}$ & 1 & $2,08 \%$ \\
\hline $\begin{array}{l}\text { Obat yang harus dihindari } \\
\text { atau dikurangi dosis pada } \\
\text { penderita gagal ginjal } \\
\text { lanjut usia (non infeksi) }\end{array}$ & 7 & $12,50 \%$ \\
\hline $\begin{array}{l}\text { Penelitian menunjukkan sebesar } \\
\text { mengalami lebih dari 1 PIM. Klasifikasi PIM yang } \\
\text { terbanyak pada RS A yaitu PIM dan kelas obat yang } \\
\text { harus dihindari pada lanjut usia sebesar 50,00 \% } \\
\text { dari keseluruhan kejadian PIM }\end{array}$ \\
\hline
\end{tabular}

Potential Inappopriate Medication (PIM) pada RS B

PIM yang terjadi pada RS A sebesar 39 kejadian pada 27 pasien dari 66 pasien. Jumlah PIM yang terjadi pada pasien yaitu :

Tabel 3. Jumlah PIM berdasarkan Jumlah pasien di RS B

\begin{tabular}{|c|l|l|}
\hline & Jumlah & Persentase \\
\hline Pengobatan tanpa PIM & 39 & $59,09 \%$ \\
\hline Pengobatan dengan PIM & 27 & $40,91 \%$ \\
1 PIM & 19 & $28,78 \%$ \\
$\geq 2$ PIM & 8 & $12,12 \%$ \\
\hline
\end{tabular}

Tabel 4. Klasifikasi PIM berdasarkan Beers Criteria 2015 di RS B

\begin{tabular}{|l|l|l|}
\hline Klasifikasi PIM Jumlah & Persentase \\
\hline $\begin{array}{l}\text { PIM dan Kelas Obat yang } \\
\text { harus dihindari pada } \\
\text { lanjut usia }\end{array}$ & 26 & $66,67 \%$ \\
\hline $\begin{array}{l}\text { PIM dan Kelas obat yang } \\
\text { harus dihindari pada } \\
\text { lanjut usia dengan } \\
\text { penyakit dan sindrom } \\
\text { tertentu obat dapat } \\
\text { memperparah }\end{array}$ & & \\
\hline Obat yang digunakan hati- & 11 & $28,20 \%$ \\
\hline
\end{tabular}




\begin{tabular}{|l|l|l|}
\hline hati pada lanjut usia & & \\
\hline $\begin{array}{l}\text { Interaksi Obat-obat yang } \\
\text { harus dihindari pada } \\
\text { lanjut usia (non infeksi) }\end{array}$ & 0 & $0,00 \%$ \\
\hline $\begin{array}{l}\text { Obat yang harus dihindari } \\
\text { atau dikurangi dosis pada } \\
\text { penderita gagal ginjal } \\
\text { lanjut usia (non infeksi) }\end{array}$ & 0 & $0,00 \%$ \\
\hline
\end{tabular}

Penelitian menunjukkan sebanyak 8 pasien mengalami lebih dari 1 PIM. Klasifikasi PIM yang terbanyak pada RS B yaitu PIM dan kelas obat yang harus dihindari pada lanjut usia sebesar 66,67\% dari keseluruhan kejadian PIM.

Potential Inappopriate Medication (PIM) pada RS C

PIM yang terjadi pada RS C sebesar 23 kejadian pada 17 pasien dari 45 pasien. Jumlah PIM yang terjadi pada pasien yaitu :

Tabel 5. Jumlah PIM berdasarkan Jumlah pasien di RS C

\begin{tabular}{|c|l|l|}
\hline & Jumlah & Persentase \\
\hline Pengobatan tanpa PIM & 28 & $62,22 \%$ \\
\hline Pengobatan dengan PIM & 17 & $37,78 \%$ \\
1 PIM & 12 & $26,67 \%$ \\
$\geq 2$ PIM & 5 & $11,11 \%$ \\
\hline
\end{tabular}

Tabel 6. Klasifikasi PIM berdasarkan Beers Criteria 2015 di RS C

\begin{tabular}{|l|l|l|}
\hline Klasifikasi PIM & Jumlah & Persentase \\
\hline $\begin{array}{l}\text { PIM dan Kelas Obat yang } \\
\text { harus dihindari pada } \\
\text { lanjut usia }\end{array}$ & 17 & $73,91 \%$ \\
\hline $\begin{array}{l}\text { Obat yang digunakan hati- } \\
\text { hati pada lanjut usia }\end{array}$ & 2 & $8,70 \%$ \\
\hline $\begin{array}{l}\text { Obat yang harus dihindari } \\
\text { atau dikurangi dosis pada } \\
\text { penderita gagal ginjal } \\
\text { lanjut usia (non infeksi) }\end{array}$ & 3 & $13,04 \%$ \\
\hline
\end{tabular}

Penelitian menunjukkan sebanyak 5 pasien mengalami lebih dari 1 PIM. Klasifikasi PIM yang terbanyak pada RS B yaitu PIM dan kelas obat yang harus dihindari pada lanjut usia sebesar $72,73 \%$ dari keseluruhan kejadian PIM

\section{Golongan, jenis dan nama obat pada resep keluar RS yang mengalami PIM}

Sebanyak 105 obat yang mengalami PIM dalam Resep Keluar Rumah Sakit. Golongan, Jenis dan nama obat yang mengalami PIM pada 3 RS di Sulawesi Utara yaitu
Tabel 7. Golongan, jenis dan nama obat yang

mengalami PIM

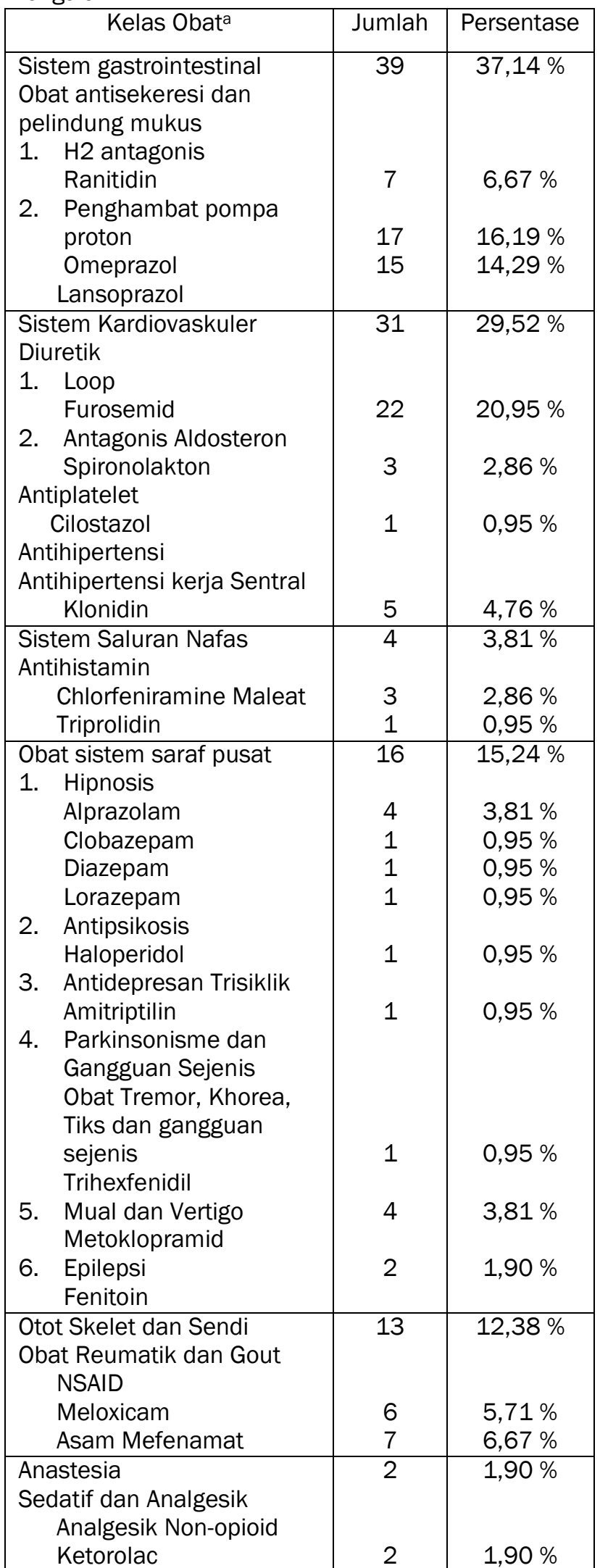

aPembagian Kelas Obat berdasarkan Informatorium Obat Nasional Indonesia (IONI)

\section{Pembahasan}

Hasil Penelitian menunjukkan Kejadian PIM pada Resep Keluar Rumah Sakit pasien lajut Usia di 
RS A, RS B dan RS C yaitu 81,26 \%, 40,91 \% dan $37,38 \%$ secara berturut-turut. Keadaan RS A, RS B dan RS C tidak mempunyai ruangan yang difokuskan pada Geriatrik (Geriatric ward) mempengaruhi pengobatan yang dilakukan. Penelitian oleh Asplund et al (2000) membandingkan antara Bangsal Geriatric dengan Bangsal umum untuk pasien lanjut usia dan hasil penelitian menunjukkan Pasien lanjut usia pada bangsal geriatric lebih pendek lama perawatan dibandingkan Pasien Lanjut Usia pada Bangsal Umum. Lama Perawatan merupakan salah satu faktor untuk mengidentifikasi keberhasilan pengobatan yang dilakukan. Semakin cepat lama perawatan pasien semakin berhasil pengobatan pasien. Keberhasilan pengobatan pasien Iansia ditentukan monitoring terhadap pengobatan pasien. Hasil penelitian ini menggambarkan pentingnya Bangsal khusus Pasien Lanjut Usia di Sulawesi Utara

Klasifikasi PIM menunjukkan seluruh kejadian PIM di Tiga Rumah Sakit yang terbanyak PIM dan Kelas Obat yang harus dihindari pada lanjut usia (50,00\%, 66,67\%, 73,91\%). Hasil tersebut sama dengan penelitian Zeenny (2017) pada resep pasien lanjut usia farmasi komunitas di Libanon yang menunjukkan Klasifikasi terbanyak di PIM dan Kelas Obat yang harus dihindari sebesar 35,5\% dari 112 PIM. Hasil penelitian menunjukkan banyak pasien lanjut usia mendapatkan obat yang seharusnya dihindari penggunaannya disebabkan efeknya yang merugikan. Hal itu menunjukkan pentingnya monitoring obat pasien.

Golongan Obat terbanyak yang termasuk dalam PIM Golongan Sistem Gastrointestinal khususnya Pemblok Pompa Proton sebesar 32 PIM dari 105 PIM (30,47 \%). Kedua terbanyak Golongan Diuretik sebanyak 25 PIM dari 105 PIM (23,81\%). Pada penelitian Zhang (2017) mengidentifikasi PIM menggunakan Beers Criteria 2015 dan Golongan obat yang terbanyak yaitu Pemblok Pompa Proton (41,9 \%). Beers Criteria 2012 menjadi 2015 salah satu updatenya penambahan Pemblok Pompa Proton yang dapat mengakibatkan jatuh dan patah tulang pada Pasien Lanjut Usia. (AGS, 2015). Hal tersebut mempengaruhi golongan obat terbanyak yang termasuk dalam PIM.

Golongan obat kedua terbanyak Golongan Diuretik yaitu Furosemid dan spironolakton. Pada Beers Criteria 2015, diuretik masuk dalam kategori obat yang digunakan hati-hati pada Pasien Lanjut Usia sehingga pemberian Furosemid pada pasien Lanjut Usia harus dilakukan monitoring kadar elektrolit.

Kelemahan dari Penelitian ini yaitu kurangnya sampel pada RS A yang kurang dapat menggambarkan PIM pada pasien disebabkan waktu pengambilan yang kurang tepat dimana data rekam medis digunakan dalam akreditasi Rumah Sakit dan Tdak dapat menentukan faktor faktor yang berpengaruh pada terjadinya PIM pada setiap Rumah Sakit.
Kesimpulan

1. Kejadian Potentially Inappopriate Medications pada Resep Keluar Rumah Sakit Pasien Diabetes Melitus Lanjut Usia di RS A, RS B dan RS C sebesar 81,26 \%, 40,91 \% dan 37,38\% secara berturut-turut

2. Klasifikasi PIM terbanyak pada Resep Keluar Rumah Sakit Pasien Diabetes Mellitus Lanjut Usia di Tiga Rumah Sakit (RS A, RS B dan RS C) yaitu PIM dan Kelas Obat yang harus dihindari pada lanjut usia (50,00\%, 66,67\%, 73,91\%)

3. Golongan Obat terbanyak yang termasuk dalam PIM yaitu Golongan Sistem Gastrointestinal khususnya Pemblok Pompa Proton (30,47 \%) dan Golongan Diuretik (23,81\%).

\section{Daftar Pustaka}

American Geriatrics Society 2015 Beers Criteria Update Expert Panel, American Geriatrics Society 2015 updated Beers criteria for potentially inappropriate medication use in older adults. J Am Geriatr Soc. 63,11 (2015):22272246.

Asplund, Kjell \& Gustafson, Yngve \& Jacobsson, Catrine \& Bucht, Gösta \& Wahlin, Anders \& Peterson, Jonas \& Blom, Jan-Olof \& Angquist, KA. Geriatric-Based Versus General Wards for Older Acute Medical Patients: A Randomized Comparison of Outcomes and Use of Resources. Journal of the American Geriatrics Society. Vol 48 (2000).1381-8. Doi: 10.1111/j.15325415.2000.tb02626.x.

Dinas Kesehatan Kota Manado, Profil Kesehatan Kota Manado tahun 2017. download http://www.depkes.go.id/resources/download/ profil/PROFIL_KAB_KOTA_2017/7171_Sulut_K ota_Manado_2017.pdf

Fick DM, Mion LC, Beers MH, L Waller J. Health outcomes associated with potentially inappropriate medication use in older adults. Res Nurs Health. 31, 1 (2008); :42-51. doi:10.1002/nur.20232.

Kemenkes RI, 2017, Analisis Lansia di Indonesia, Pusat Data dan Informasi Kementrian Kesehatan

RI.http://www.depkes.go.id/download.php?file= download/pusdatin/lain-

lain/Analisis\%20Lansia\%20Indonesia\%202017. pdf

Routledge PA, O'Mahony MS, Woodhouse KW. Adverse drug reactions in elderly patients. $\mathrm{Br} J$ Clin Pharmacol.57, 2 (2004);121-126. doi:10.1046/j.1365-2125.2003.01875.x

WHO, 2019, Health topic Diabetes, https://www.who.int/health-topics/diabetes

Yakaryılmaz, Funda Datli, and Zeynel Abidin Öztürk. "Treatment of type 2 diabetes mellitus in the elderly." World journal of diabetes vol. 8,6 (2017): 278-285. doi:10.4239/wjd.v8.i6.278 